\title{
Knowledge-sharing, control, compliance and symbolic violence
}

\begin{abstract}
Recent developments in control hold that professionals are best managed through normative and concertive as opposed to bureaucratic and coercive mechanisms. This post-structuralist approach appeals to the notion of congruent values and norms and acknowledges the role of individuals' subjectivity in sustaining professional autonomy. Yet, there remains a risk of oversimplifying the manifestations of such control initiatives. By means of an in-depth case study, this article considers the challenge of implementing a knowledge-sharing portal for a community of R\&D scientists through management control initiatives that relied on a blend of presumed 'peer pressure' and the rhetoric of 'facilitation'. Arguing that traditional approaches such as normative/concertive control and soft bureaucracy only partially explain this phenomenon, we draw from Pierre Bourdieu's concept of 'symbolic violence' to interpret a managerial initiative to appropriate knowledge and affirm the structure of social relations through the complicity of R\&D scientists. We also examine how the scientists channelled resistance by reconstituting compliance in line with their sense of identity as creators of knowledge.
\end{abstract}

Key words: knowledge, control, compliance, resistance, symbolic violence, Bourdieu 


\section{Introduction}

Following Waring and Currie's (2009, p.767) finding that 'attempts to engender normative change and compliance amongst clinicians remain problematic,' this paper puts forward the argument that understanding how organizations 'manage' professionals requires a shift in emphasis away from the contemporary emphasis on how managers impose normative control strategies to how they construct willing compliance. With reference to Bourdieu's concept of symbolic violence, we examine how an organization pursued a subtle form of control to realize knowledge sharing, relying on the acquiescence of $R \& D$ scientists who nevertheless accomplished some degree of resistance by defining compliance on their own terms. Symbolic violence refers to the exercise of force or power upon social agents with their complicit acceptance (Bourdieu, 1991; Bourdieu \& Passeron, 1977). Bourdieu illustrates this concept in various ways, such as in gift-giving, an act whose embedded reciprocity imposes a form of domination over the recipient, ultimately misrecognizing the economic reality of the exchange, and in the process realizing a subtle form of control. Thus, we contribute to the understanding of control by problematizing compliance and discovering how it constitutes a manifestation of employee resistance.

Recent critiques of normative control point to the increasing tendency to distract employees' attention from the dysfunctions of conventional controls while ultimately only prescribing 'freedom around control' (Fleming \& Sturdy, 2011). Drawing from Weber and Crozier, Courpasson (2000, p. 142) posits the notion of 'soft bureaucracy' whereby domination arising from the legitimate use of power is not 'exerted by means of, for example, violence, direct punishment or local hierarchical supervision, but through sophisticated managerial strategies.' The notion of 'soft bureaucracy' to achieve 'political centralization' while recognizing that organizations are more entrepreneurial and decentralized is one that we find particularly pertinent for this paper. Courpasson's purpose is to understand domination in terms of the strategies senior management develop 'to control elite groups' (Courpasson, 2000, p. 152). He found that senior management resorted to a strategy of 'proving and normalizing professional success' which included assessment grids and criteria to define success, and a strategy of 'objectivating personal responsibility' to manage through pragmatic performance indicators.

In our case study, a global confectionary firm we name Confect, senior management developed no such metrics. Rather than produce mechanisms for defining expected activities, and attribute initiatives and decisions, senior management treated a highly publicised knowledge-sharing system as purely voluntary. We wanted to look beneath the stated notion 
of 'voluntary participation' to understand why management would go to the lengths of creating a top-level global knowledge management team to oversee this resource-critical initiative and yet treat it as purely voluntary, put little or no visible mechanism in place to monitor use and effectiveness, and leave it entirely to the discretion of a community of researchers with little mention of 'bottom-line' implications. We seek to shed new light on the organizational pursuit of legitimacy by examining how domination is realized not through managerial strategies informed by 'threat and potential repression' (Courpasson, 2000, p. 159), but through a subtle appeal to willing compliance that is neither extracted through performance management mechanisms nor stimulated by rewards as in normative control. As we discuss below, normative control itself is prone to creating oppressive effects (Barker, 1993).

We contend that both normative and coercive approaches only tell part of the story, and do not sufficiently account for compliance either as genuine acquiescence or a form of resistance. Furthermore, we argue that compliance does not, unlike orthodox normative control, necessarily assume that employees will subscribe to the managerial narrative because it is consistent with their own values and aspirations. Thus, we draw from Pierre Bourdieu's social theory to examine how the quest for compliance relies on mis-recognizing control strategies. Our key contribution is to demonstrate the use of power which relies not on coercive or normative control but on the (Bourdieusian) complicity of highly autonomous professionals (in this case R\&D scientists) who are nevertheless prepared to define their compliance on their own reflexive terms.

The context of this analysis is a knowledge-sharing corporate initiative rather than control for its own sake. It is therefore necessary to set out briefly the case for knowledge management. Prior research has tended to focus on deriving 'rents' from productive activities (Grant, 1996), the integration, diffusion, and protection of knowledge (e.g. Ambrosini \& Bowman, 2001; Nonaka \& Takeuchi, 1995), thus ensuring effective sharing and preventing leakage (Tallman \& Phene, 2007). A more critical strand has developed which looks at how knowledge is reified, the political, ideological, identity, situated, and power issues associated with 'managing' and appropriating knowledge (e.g. Bowman \& Swart, 2007; Brivot, 2011; Collins \& Smith, 2006; Kamoche \& Maguire, 2011; Schultze \& Stabbel, 2005; Tsoukas, 1996), thus shedding light on how and why individuals might act in their own self-interest. Previous attempts to understand how knowledge management systems secure the knowledge of organizational members and disseminate it to other potential users have drawn for example from social capital theory (Dyer \& Nobeaka, 2000; Inkpen \& Tsang, 2005). Foss, Husted and Michailova (2010) found that much of the knowledge sharing literature is concerned with 
constructs, processes largely at the 'macro', i.e. collective/organizational levels. They call for, inter alia, research into how governance mechanisms shape employees' knowledge-sharing behaviour, a call we heed with respect to the role of control.

The debate on experts/expertise, professionals, identity and culture within knowledgeintensive firms (KIFs) (Alvesson, 1993; Robertson \& Swan, 2003) is particularly pertinent to this paper. For example, Robertson and Swan (2003) explore the theme of knowledge workers conniving in their own control with respect to Willmott's (1993) notion of slavery. Thus, 'instead of top-down normative control, where those in power generate norms for those who are not, $[\ldots]$ consultants themselves developed strong norms based on ambiguity that secured both their own freedom and their own slavery to the organization' (Robertson \& Swan, 2003, p. 852). Reed (1996) suggests that technologies not only permit high degrees of visibility and transparency, but they also lead individuals to internalize 'self-discipline and control'. Individuals allow their subjectivity to be defined through surveillance (Sewell, 1988), as transparency and visibility prevent them from hiding from the 'supervisory gaze' (Reed, 1996). This is an important analytical tool for unravelling control that is deliberately geared at subjugating the individual through normalization. However, where efforts at normalization through disciplinary control and subjection (Foucault, 1975) are either incomplete or ambiguous as in Confect, it is necessary to seek alternative explanations for actions consistent with this apparent 'self-discipline'.

Confect introduced a knowledge management system in a subtle and non-threatening manner which they described in terms of 'leadership and facilitation', and expected to rely on peer pressure rather than overt control. Yet, to the extent that social actors ultimately determine the extent and degree of their involvement in sharing knowledge, the organization's capacity to secure legitimacy for the knowledge appropriation system is potentially circumscribed. This suggests a need to determine how individual reflexivity constitutes a potential challenge to managerial exhortations to share knowledge and how it constitutes a form of resistance. While recognizing that employee resistance is closely tied to managerial control mechanisms (e.g. Jermier, Knights and Nord, 1994; Waring \& Currie, 2009) the intriguing question for us was how management expected to secure compliance without overtly relying on normative or coercive control. Pierre Bourdieu's work seemed appropriate in our analysis because of the way Bourdieu treats power, control, and legitimation in social settings defined by the use of capital in organizational and institutional fields in which there is no visible conflict (Oakes, Townley, \& Cooper, 1998), which is particularly pertinent to our case study. In particular, we consider Bourdieu's concept of symbolic violence suitable because it is about relations of 
domination, and for its focus on the struggles between 'fractions' within 'dominant classes' united by habitus rather than class conflict, and its concern with tensions that are not always recognized for what they are (see also DiMaggio, 1979).

We seek to examine how a 'dominant' authority (in this case a senior management team) sought control with the complicity of the 'dominated' (R\&D scientists) (Bourdieu, 1991; Bourdieu \& Passeron, 1977). Yet, to the extent that the latter exercise agency and are prepared to calibrate their compliance, the boundary between 'dominant' and 'dominated' becomes blurred. Our focus on Bourdieu's less well-known concept of symbolic violence does not imply that symbolic violence can be viewed as separate from his better known concepts, capital, habitus and field. In fact, these four are best seen as 'an architecture' of interrelated concepts, whereby symbolic violence is objectified in physical objects, certificates and other forms of cultural capital as well as in persons as habitus (Robinson \& Kerr, 2009; Wacquant, 2002).

Prior research has considered how professionals such as medical practitioners (eg Doolin, 2002; Waring and Currie, 2009) and lawyers (Brown and Lewis, 2011:880) consent to participate in knowledge creation and to adhere to bureaucratic procedures in ways that affirm their status and identity. Our purpose is to examine how this compliance is triggered through a managerial narrative which operates by concealing (ie mis-recognizing) its intent. Below, we offer a brief critique of the normative control literature, and set out our rationale for positing a symbolic violence approach. We then offer the case study, and consider how the scientists' own experience and conception of knowledge-sharing challenged yet legitimized the managerial knowledge-sharing initiative. We conclude with some thoughts for further research.

\section{Control, resistance and complicity}

Whereas the definition of the artefacts of knowledge was previously accompanied by important sociological questions about the powerful role of the 'technocracy', (e.g. Bell, 1973; Drucker, 1993; Galbraith, 1967), the current preoccupation with knowledge management is largely about constructs (Foss et al., 2010) and the mechanisms of sharing knowledge (e.g. Dyer \& Nobeoka, 2000; Hansen, 2002; Tallman \& Phene, 2007). This approach appears not to have fully engaged the question of power and control (see also Bartunek, 2002; Clegg, 2002; Hinnings, 2002). This is a worrying trend given what we know about the role of power in and around organizations, the prevalence of management controls on human behaviour, the "politics of expertise' (Alvesson, 2001; Drazin, 1990; Reed, 1996), trust, domination and legitimacy (Courpasson, 2000; Grey \& Garsten, 2001), and the quest for emotional identification with the 
firm (Fleming \& Sturdy, 2011; Kunda, 1992). Following earlier debates on the tension between rewards and control over expertise (Reed, 1996), scholars have begun to explore issues such as how professionals negotiate claims to 'property' in their knowledge (Pinnington, Kamoche, $\&$ Suseno, 2009), and the 'struggle of ownership' between actors engaged in contests over 'value capture' (Bowman \& Swart, 2007, p. 488).

Traditionally, scholars have related normative control to professionals as it departs from coercive control and relies on instilling shared values, beliefs and attitudes (Etzioni, 1964). It is consistent with 'clans' which rely on socialization to eliminate goal incongruence, high degrees of interaction and frequent communication and sharing of ideas (Ouchi, 1979; Turner \& Makhija, 2006). A critique has emerged which challenges the insidious effects of normative/concertive forms of control which rely on fostering and rewarding the desired norms and values (e.g. Alvesson, 1993; Barker, 1993; Kunda, 1992; Robertson \& Swan, 2003; Willmott, 1993). Barker (1993) found that 'concertive control' which also relies on normative rules and value consensus generated through members' interactions ultimately achieved even tighter control. Through shared values they themselves created and policed, the 'team members had become both their own masters and their own slaves' (Barker, 1993, p. 433). Robertson and Swan (2003) have shown how normative control was achieved through the regulation of identity based on elitism, whereby scientists lent their loyalty and compliance to corporate objectives and consented to collaborate on projects because they effectively tied their identity as 'the experts' to the corporate identity of elitism the firm fostered. Fleming and Sturdy (2011) challenge the authenticity of the experience of identifying with the work itself through playful expressions of self.

Taken together, these contributions demonstrate that the presumption of goal-congruence, interest-alignment and shared values is prone to generating oppressive effects (Kunda, 1992; Willmott, 1993). We build on this critique to re-examine the nature of acquiescence that is framed in terms of the seemingly 'willing' participation of employees. In Barker's (1993) case study, peer pressure was effective in creating a control regime that worked through shared value consensus. Similarly, Raelin (2011, p. 142) argues that team members can 'presumably control themselves collectively by identifying those among the group who are shirking or failing to achieve productive targets'. At Confect, management relied on presumed peer pressure which they hoped would realize compliance; yet where pressure peer came into play, and it functioned in surprisingly different ways.

Evidence shows that the use of power and control triggers acts of resistance ranging from overt, antagonistic/recalcitrant actions towards capitalist production, to a more dialectical, 
negotiated scenario and the appeal to subjectivity and the discursive practices individuals engage in to co-opt and adapt bureaucratic procedures, to reclaim their identity and redefine power relations (Alvesson \& Willmott, 2002; Ball \& Wilson, 2000; Collinson, 1994; Courpasson, 2000; Delbridge \& Ezzamel, 2005; Doolin, 2002; Symon, 2005; Thomas \& Davies, 2005; Waring \& Currie, 2009). Thomas and Davies (2005, p. 685) argue that the tendency to construct resistance 'within a negative paradigm, a worker corps kicking back against management control' means that certain groups and certain nuances of resistance, and motivations for resisting remain under-researched. Delbridge and Ezzamel (2005, p. 606) argue that the debate on control based on values, traditions and beliefs has led to further interest in control through 'internalized compliance' as opposed to 'external constraint'. Fleming (2012) argues that control is generating new forms of resistance which allow individuals to seek meaning in other aspects of their lives, rather than identifying with the organization.

It seems to us there is a need to enhance understanding of the nature of compliance, how it is elicited, and how it recursively constitutes a form of resistance particularly amongst professionals such as R\&D scientists who enjoy high degrees of operational autonomy and whose knowledge is closely woven into their conception of identity. While Nonaka and Takeuchi (1995) describe managers as 'knowledge-engineers', a view that invests in managers positional legitimacy in the exercise of power and control, Swan, Scarbrough, and Robertson (2002) have characterized managers' ability to exploit 'communities of practice' in order to legitimize new practices where they recognize they are up against more powerful professional groups. These scenarios highlight the contested nature of the knowledge-appropriation context, one in which tacit knowledge is not directly appropriable because it cannot be directly transferred (Grant, 1996), and where it cannot be taken for granted that people will willingly share knowledge (Currie \& Kerrin, 2003; Konstantinou \& Fincham, 2010). This in turn raises important questions not just about power asymmetry but also about identity, whereby individuals either through strong cohesive groups or individually come to identify themselves with certain work practices and determine the form and extent of their engagement with technology (Shamir, 1991), or with management practices (Doolin, 2002).

\section{Bourdieusian symbolic violence}

The significance of Bourdieu's relational theory of sociology which embraces his key constructs, capital, habitus, and field is now increasingly acknowledged (DiMaggio, 1979; Emirbayer \& Johnson, 2008). Bourdieu argues that the possession of capital (e.g. cultural, 
symbolic, economic, juridical, educational), confers on the holder powers that have the potential to re-define the configuration of power relations. An emergent body of work has focused on these three constructs (e.g. Cooper, 2008; McLeod, O’Donohue, \& Townley, 2009; Morean, 2009; Mutch, 2003; O’Mahoney, 2007; Oakes et al., 1998; Townley, Beech, \& McKinlay, 2009). A Journal of Management Studies special issue (Lampel \& Meyer, 2008) was devoted to the notion of 'field-configuring events' where the conception of field drew heavily from Bourdieu's work.

Symbolic violence manifests itself in three ways which are key to our analysis: it seeks to change 'what is at stake' through the power of pedagogy; it invokes mechanisms of social control which are not always explicit; and it works through mis-recognition, realizing while denying social realities (Bourdieu, 1998, 1977; Bourdieu \& Passeron, 1977). Pedagogy is equivalent to learning a new language, and more importantly, acquiescing in the legitimacy of this language and accepting it as the legitimate way to communicate. Bourdieu and Boltanski (1984) illustrate this by showing how a language assumes legitimacy even amongst those who do not speak it but nevertheless accept its superiority to theirs as in the case of an 'official' language. The 'dominated' succumb to meconnaisance (misrecognition) brought about by the reconnaissance (recognition) of the legitimacy of the superior language (Bourdieu \& Boltanski, 1975). Thus, the use of a 'superior language', gift, or the educational system imposes a 'cultural arbitrary' to express the objective interests of the dominant groups/classes.

The 'cultural arbitrary' is a condition that expresses the arbitrary imposition of power by misrecognizing its effects and purpose and ultimately reproducing and legitimizing social inequality. Moore (2004, p. 447) captures the essence of the cultural arbitrary as follows: 'Once it is acknowledged that the positions and relations of the cultural field are valorized by power relations rather than by aesthetic qualities inherent to them, then they can be recognized as arbitrary and their imposition through pedagogic action seen as constituting "symbolic violence". Thus, dominant groups conceal the fact that their cultural power (achieved for example through a 'superior' language) reproduces while disguising social stratification and class interests (Bourdieu, 1977; Bourdieu \& Passeron, 1977). The effect of symbolic violence is that the dominant group determines the appropriate way to function, and acquires legitimacy for arbitrary power relations - a 'cultural arbitrary' - (in our case a knowledge management portal) through the complicity of the 'dominated'. There is nothing inherently or intrinsically superior about the portal; it has meaning only relationally, meaning that it reflects the tastes and interests of those who 'arbitrarily' hold power (Bourdieu \& Passeron, 1977). Robinson and Kerr (2009) show how symbolic violence becomes a way of conceptualizing legitimate domination, where structural 
domination is misrecognized by followers as 'charm', or 'as the attributes of the 'natural leader' (Robinson \& Kerr, 2009, p. 881).They have also examined how symbolic violence in banking came to be maintained by 'economic violence' which in turn counted as symbolic capital outside the organization; thus symbolic violence truly becomes a relationship of domination (Kerr \& Robinson, 2012). Besides the educational context (Moore, 2004), the concept of a 'cultural arbitrary' is beginning to generate some interest in organization studies. For example, Kamoche and Pinnington (2012) have examined the ideological underpinnings of organizational spirituality through the lens of symbolic violence, with reference to the cultural arbitrary of managerial power and the effects of pedagogy.

By relying on complicity as opposed to coercion, symbolic violence has resonances with 'concertive control' in self-managed teams, and members' collaborative actions (Barker, 1993), but goes further by tying complicity to misrecognition, ideology and legitimation. While it appears to be taken for granted that socialized professionals grant the organization their complicity as they respond say to symbolic and financial rewards (Kunda, 1992), symbolic violence allows us to problematize complicity and also to understand how it constitutes a form of resistance. Conflict and resistance are as prevalent as compliance and consent (Jermier et al., 1994). Resistance manifests itself to the extent that compliance is never a fait accompli but is in part contingent on the way individuals define the form and extent of participation in managerial exhortations to share knowledge. Thus, we position our contribution in terms of how management sought voluntary compliance for a knowledge-sharing portal while misrecognizing the power-political dynamic that was central to realizing managerial control.

\section{The Confect Case Study: research setting and methodology}

Confect is a global confectionary maker which employs about 60,000 people worldwide. We selected this firm in order to examine the circumstances surrounding its introduction of a new knowledge management system which, during a two-year period after its inception, had created a buzz in the Australia media. It seemed appropriate to opt for a case study approach that would enable us to hear the voices of the management team that was spear-heading the initiative, as well as a sample of R\&D scientists for whom the knowledge-sharing portal had been created. Our purpose was to interpret the phenomenon at the level of meaning, to develop theory as opposed to pursuing empirical validation. This approach is consistent with prior work on control (e.g. Barker, 1993; McLoughlin, Badham, \& Palmer, 2005; Robertson \& Swan, 2003) 
and on Bourdieu's social theory (e.g. McLeod et al., 2009; Morean, 2009; Oakes et al., 1998; Robinson \& Kerr, 2009) which informs our analysis.

We held a total of fifteen interviews, three in Phase 1 ( 1 male, 2 female), and twelve in Phase 2 (6 male, 6 female). Phase 1 took place in Australia in 2007, with the globally dispersed executive Knowledge Management Team (KMT) which comprised of three people: Global Technical Director (GTD), Knowledge Process and Data Manager (KPDM) (both based in Australia); and Technical Knowledge Manager (TKM) (based in the UK). The KMT reported to the VP, Technical Knowledge, who was based in the USA. This team was responsible for introducing a knowledge management system for the company's research scientists and technicians. Extensive interviews based on a semi-structured questionnaire were conducted with the three executives: face-to-face with the two Australia-based ones, and by teleconference with the UK-based one. Using standard case study protocol (Yin, 1994), respondents were asked open-ended questions followed by probing questions. These interviews, which on average lasted ninety minutes, covered a wide range of topics on the company's objectives in setting up a knowledge management system, the types of knowledge-sharing the system was designed to accomplish, the challenges that were being faced in the process and how these initiatives were linked to human resource practices.

Access to scientists was not granted until three years later (Phase 2), a delay which ultimately worked in our favour by enabling us to take stock of how the knowledge management system had unravelled, and the extent to which it had become embedded and accepted. Nevertheless, access was limited, and we interviewed five managers and seven R\&D staff, four in the UK and three in Australia. The approach we took and the number of subjects interviewed are considered adequate for a case study analysis (Yin, 1994; Easterby-Smith, 1994). For Phase 2, the interviews in Australia were by telephone and those in the UK face to face. The R\&D staff and Phase 2 managers were selected from those who were available and willing to speak to us. The interviewees were evenly spread; amongst the seven males: four managers and three R\&D staff; amongst the eight females: four managers and four R\&D staff. In Phase 2 of the project, interviews lasted from 30 to 60 minutes. Questions to the R\&D staff revolved around their reasons for, and experience of knowledge-sharing, and their exposure to the knowledge-sharing technology. We did not specifically seek to confirm/corroborate the claims made by the managers, but instead wanted to allow them to tell their own story of knowledge-sharing.

All the interviews were tape-recorded and transcribed. We triangulated them with archival materials relating to the strategic thinking behind the inception and operation of the 
knowledge management system, various published reports, some company newsletters, and our field notes. Guided tours of the office, factory and recreational premises where we were able to observe people at work, also gave us a useful glimpse into the working lives of the employees, the pressures they endured to deliver new products through collaboration, and the sense of community they wished to create and be a part of. The data were analysed using inductive techniques in order to gain in-depth knowledge of a process within a single case study, as opposed to capturing a snap-shot at a point in time (see also Ragin, 1994). In an approach consistent with narrative analysis and interpretation (Gabriel, 2000; Pinnington et al., 2009), the transcribed responses were checked against the tape-recordings and field notes, coded according to topic and subjected to a series of iterations until specific themes and stories began to emerge. These themes and stories were corroborated against each other and doublechecked against the field notes, thus ensuring the integrity of the data. Our analysis was guided by replication rather than sampling logic (Dyer \& Wilkins, 1991; Eisenhardt, 1989; Yin, 1994), and aimed to critique and extend extant theory on control within the context of knowledge management.

\section{Research findings}

The centre piece of the knowledge management (KM) system at Confect was an online sharing space, hereafter referred to as Confect-Portal, in which project or product research 'communities' were encouraged to participate through interaction and knowledge-sharing. The objective was to break down barriers so knowledge could be leveraged and diffused across the organization. This is consistent with the view that knowledge-sharing systems are designed, inter alia, to "motivate individual members to participate and contribute knowledge to the collective good' (Dyer \& Nobeoka, 2000, p. 348). The KMT maintained that there was no compulsion to participate and that the purpose was to provide a virtual space whereby functionally-viable content would emerge organically through voluntary collaboration and peer pressure, and where interaction would ultimately drive performance. However, the findings reveal some fundamental differences between the way the KMT conceived of Confect-Portal and the way the R\&D scientists understood and utilized it. We juxtapose these realities and proceed to offer a theoretical interpretation of what we perceive to be management's underlying purpose in creating the portal. First we discuss our initial observation of two themes which emerged as characterizing the functioning of the knowledge-sharing mechanism, and which 
pave the way for an explication of symbolic violence: (1) leadership and the rhetoric of facilitation, and (2) subtle control through presumed socialization.

\section{Leadership and the rhetoric of facilitation}

The approach to knowledge management/sharing was framed in terms of leadership and empowering people:

We do have a top-down approach, providing information that the leaders can communicate. The leaders are not going to be out there driving the knowledge activities, but they have to be visibly supporting them ... but the knowledge that is created is really happening at the ground level, it's down in the communities themselves. (GTD)

In practical terms, leadership in knowledge sharing was operationalized amongst managers by including 'collaboration' amongst the competences (or 'leadership imperatives') that managers are judged upon. As for empowerment, a manager reported:

I think we've worked on our leadership. I think that isn't really a barrier. I think they see that there's value in the job they're doing or my team is doing, and they're quite happy to go along, so long as we give them empowerment and they need to be led through that. (KPDM).

After some initial resistance, the KMT understood that leadership based on a directive approach would not work, which shows they acknowledged the limitations of bureaucratic control for appropriating knowledge. According to the GTD, initial efforts to 'obviously push people into sharing' proved counter-productive and it was considered more effective 'to note and encourage positive behaviours and quietly discourage negative ones'.

People are sceptical about changing the way they've always done things ... but once you sit down with them and explain the benefits so they get something out of the database then they're more likely to contribute, but it's just getting that change in direction that's hard. It takes me, really, physically to have a meeting with those individuals to really change their behaviours, and there is not enough of me to go round. (TKM)

We're not specifically targeting, you know, trying to take the tacit knowledge, and making it explicit and putting it into a system because you never quite know what is going to be useful for people, like something that has been useful for me might have no use at all for anyone else. But then something that I'm not even aware of could be made great use of by someone, maybe. (GTD)

This position reflects the challenge Confect faces in adopting a suitable method to achieve 'knowledge capture'. The GTD's statement exemplifies the ambiguity surrounding the 
value of knowledge possessed by the scientists, as well as the potential futility of micromanaging the knowledge-sharing process. According to the GTD, while the ultimate purpose of knowledge management was to 'get people to share what they know, and to use that information in order to generate some benefits', the role of the KM team was 'to get people to interact and share knowledge without letting the employees feel that managers are applying too much control', hence facilitation, which enabled a much more subtle form of control.

Facilitation, as a surrogate for leadership and control, was the catchphrase that drove through the KM experience at Confect: facilitation from top to bottom, from managers to scientists and amongst the scientists themselves and even across functions. While the portal's key customers are the R\&D group, the ethos of facilitation was expected to spread across the firm. However, we found only scanty evidence of how it worked in practice, which leads us to the view that it was more hype and aspiration than a concrete and realizable strategy.

The rest of the organization is watching what we're doing ...like the HR [group] have shared a lot more information based on them coming and discussing with us what we're doing ... the Finance people have done the same. So, though we haven't got direct responsibility for those areas, what we're doing is influencing them. (GTD)

The above shows how the expected effect on other departments lends credibility to, and is a potential source of legitimacy for the KMT's knowledge-sharing initiative. The expression 'facilitation' was used repeatedly to signal the idea that there was no compulsion, and that management's purpose was merely to create an enabling environment, even though there was no mechanism to evaluate the system, unlike the assessment grids and criteria Courpasson (2000) found. Except for some basic internet tools that kept tabs on frequency of visits (i.e. portal activity), there were no tangible metrics to measure the effectiveness of Confect-Portal as a knowledge-sharing and networking system. Instead, management relied upon ambiguous observations that included: subjective perceptions about 'volume of collaboration', 'strong pool of resources', perception of 'faster and bigger results', 'enhanced sense of community', 'selflessness', 'enhanced trust', etc.

It was noteworthy that some of the product communities took the initiative to engage in some form of self-evaluation which was about improving themselves, and which demonstrates how they chose to assess participation on their own terms based on the meanings they themselves attached to the portal. 
... we meet at an innovation forum once a month and share issues like are we joining up effectively and what can be done to improve. (Innovation Planner)

One example of facilitation in action which also served as a form of positive reinforcement was when an American team started to research fruit-flavoured beverages. Working through the portal, they discovered that a European team had recently developed a fruit-flavoured product. The KM team reportedly played a key role in facilitating an understanding of the need for the European team to pass on their knowledge to 'avoid reinventing the wheel'. Similar initiatives were cascaded through public recognition in newsletters, praise and by facilitating emulation in the rest of the community. The KMT did not believe facilitation was a foregone conclusion. The GTD reported that facilitation is prone to 'drying up, and you therefore need continuity through management initiative', which meant resorting to residual managerial control. Facilitation thus emerges as the subtle use of power to influence behaviour through social interaction, but if that failed, other forms of control (couched as 'management initiative') could be employed. The challenge for the global KMT is how to ensure that managers remain the 'knowledge engineers' (Nonaka \& Takeuchi, 1995) who are in the driving seat and yet remain inconspicuous in order not to alienate the community of scientists with obtrusive control mechanisms. Yet, questions arose as to the efficacy of the facilitation narrative when some managers who managed $R \& D$ staff appeared to be inadequately informed about the KMT's purpose.

I thought [GTD] was setting a couple of intranet sets - where you can go and post up information. I don't know what specifically [GTD] had done only because he was involved in so many different things and I wasn't involved in most of them. (Regulatory Affairs Manager)

This ambiguity reveals the limits of facilitation, and suggests to us the beginnings of mis-recognition. The KMT correctly assessed the significance of collaboration and teamwork, but their assumptions about how the process of scientific collaboration worked did not entirely tally with the scientists' own experience. All the scientists agreed that their work involved a high degree of collaboration, by as much as $50 \%$ to $80 \%$, and $100 \%$ in the case of one Innovation Planner. They also agreed that some form of virtual sharing space was crucial for their collaboration as it offered added value to the 'traditional mechanisms' such as telephones and email. The passive and exclusive nature of the portal was captured as follows:

It's not so much conversational, it's more of a repository for results you might have gained or reports you've written or information you've generated that you want everybody to share or you'd like people to look 
at. They're only accessible to people within that project team. (Polymer Chemist)

Similarly, the scientists tend to have their own personal networks that they can use to identify potential collaborators, and which do not need to be mediated through a public portal instigated and managed from the top. The other notable shortcoming of the system was that certain categories, e.g. junior scientists could not post their ideas directly and had to go through a supervisor. As one Consumer Science Scientist said: 'it's more really kind of an archive to look back at but it's not actually interactive information sharing.' This obstacle was not apparent to the KMT. The two most commonly cited reasons for not engaging with the portal were: lack of time, and the existence of alternative knowledge-retrieval and sharing mechanisms which were more user-friendly, some of which were offshoots of Confect-Portal. The foregoing demonstrates that the portal was not monolithic and that scientists had found ways to modify or navigate around it, which demonstrates both agency and a form of resistance that challenged the KMT's position and enabled the scientists to re-define participation and knowledge-sharing.

\section{Subtle control through presumed socialization}

Control relied on elements of clan and normative forms: the use of a virtual team which fostered interaction and communication, a shared sense of community amongst researchers united in their collective scientific knowledge, and a social context where specific behavioural performance and outcomes cannot be prescribed with any specificity nor are they directly measurable. Clan controls target longer-term and broader tasks and goals (Turner \& Makhija, 2006), a characteristic which is consistent with the ambiguity inherent in the functioning of Confect-Portal. The nature of the work itself is not ambiguous, as the scientists are charged with researching and delivering new recipes and products, and are subject to standard performance management. Following Ouchi (1980) and Wiener (1982) we argue that the research scientists were presumed to act in the interests of the organization through their dayto-day work, and were expected to lend their commitment to the knowledge-sharing initiative (hence to the organization) without coercion and in the absence of overt surveillance (hence the lack of performance criteria). To further accentuate the voluntary nature of participation, formal rewards were deliberately excluded from this initiative. The KMT instead capitalized on the notion of intrinsic satisfaction under the assumption that public recognition and symbolic rewards were more consistent with organizationally-socialized professionals (see also Kunda, 1992). 
Scientists are interesting creatures. You know, a public recognition goes a long way ...they like to be patted on the back. (GTD)

... we're giving a lot of public recognition to people who have shared, and that has changed the behaviour in a positive way rather than going out and looking for the negatives ... we've got a monthly newsletter that goes out to a couple thousand people...the stories that these people got together and did that and did that great, with links back to the Portal if they want to go back and look at the information, and you can see, you know, that when the newsletter goes out, the visits to the site go up and ... it's more of a carrot approach than a stick approach. (GTD)

People feel really recognised and rewarded for being in the newsletter... We've introduced a new feature called 'tales from the field', which allows us to go out there and talk to people ... what they are doing everyday rather than the senior leaders telling them what to do. That's been very successful ... and they've found it really rewarding. They may have been recognised when they're going round their business and people say 'oh I read that...' and that works well. (Technologies and Engagement Manager)

Pressed further on the benefits to the individual, she said:

I think that one of the ways that they are rewarded is through the newsletter ... and then obviously we all have our performance review. If they come up with a really good idea they get recognised from their peers ...that's what makes them proud, that's what makes them feel recognised and rewarded, the fact that they've created this product that's now in the stores ... that's the big success. (Technologies and Engagement Manager)

This positive reinforcement of behaviour in upholding consensual values and collective discipline, which typifies 'concertive control' (Barker, 1993), served management well because it freed them from having to use more directive, coercive, or bureaucratic forms of control. Comments by R\&D staff about the extent of voluntary sharing attest to this:

Most people are keen to look at new systems, maybe it's the scientist in them but they are happy to have a go. I have not found any resistance whatsoever here. (Data Specialist)

The organizational culture was often cited to explain the willingness to share:

We do have a culture of people who are really friendly and really open which I think helps. People have actually said when they come here, what a lovely bunch of people there are, everyone's really welcoming. Perhaps it is a culture that the founders have built and from the beginning their whole culture was around the people, looking after the 
people and nurturing the people. (Technologies and Engagement Manager)

Thus, while the KMT relied on socialization through the R\&D scientists' presumed commitment to their community of practice, they were careful not to take it for granted that the organization could appropriate it, hence signalling the limitations of normative control:

When you look at people leaving the company or department, have you actually captured that knowledge? ... there's always going to be information that they store in their heads that you're never gonna get to. (KPDM)

When someone actually leaves, we realize that we haven't captured the information that we need to. I'm doing more mentoring programmes and things like that ... we don't have any sort of organized approach. It's much more ad hoc and loosely implemented. It's a gap in our programme. (TKM)

The foregoing leads us to consider how the realities of sharing knowledge and resistance might be understood.

\section{The limits of sharing: resistance in action}

This section considers how sharing knowledge was shaped by the realities of the scientists' training and professional socialization and how these scenarios constitute a form of resistance. Managers believed that the two most common reasons for failing to participate in the Portal were lack of time and too much information.

A big challenge is people thinking that they don't have time to share or to talk ... it's the attitude, it's the behaviour that people think they've got such big deadlines ... so that they don't make time for those conference calls or for networking time. Often those times could actually save them time on their projects. (TKM)

I have not encountered people being negative. People don't mind sharing but it's the time to share. The forum time and time differences hinder that ... Getting people at the same time is the difficult bit-whilst we tell people it's a great opportunity. It's something that they say they'll look at, at some point. (Process Systems Manager)

The KMT believed that the potential for hoarding knowledge did exist, and that it was driven by selfish interests, and could be linked to concerns about job security and loss of power:

There's probably a little bit of reluctance to share because people think they are the holder of information the company couldn't do without. (KPDM) 
They're not giving up their baby. They're scientists. They work two years on something, and just hand over all their learning to someone they haven't met before? (TKM)

We've got experts in their field who've been in the company for a long time. And if they write that knowledge or the processes or things down and give them to someone else, they've lost, you know, they may lose, they feel they've lost part of their power and that leads to low employability ... (TKM)

The view above is particularly pertinent as it demonstrates that managers were aware that power is implicated in the knowledge appropriation regime, and was therefore a potential source of resistance. It was noteworthy, however, that the scientists rejected the possibility that people failed to share for reasons of personal career interests (cf Konstantinou \& Fincham, 2010). Similarly they did not support the management view that there was too much information.

Our biggest problem is that there's too much information on there and sometimes people don't know how to find it. (Technologies and Engagement Manager)

The scientists knew where to find information and how to locate potential collaborators. Their concerns were about the Portal not being 'conversational', 'interactive' and more importantly, resistance was framed in terms of professional diligence, reputation and identity.

If you work in a project team and the results are very crucial for the business you might not want your senior person is already seeing results when it's not really thought through finally ... There is a lot of politics, I would say. It has more political reason than anything else ... even the draft versions we wouldn't let get out ... We don't want misinterpretation, we're protecting ourselves. (Consumer Science Scientist).

It is noteworthy that this person saw the process as political, in the sense of avoiding creating the wrong impression and inviting blame, as much as it was also about protecting one's reputation.

People can see that you're making conclusions prematurely so every other piece of work you do is then looked on with less gravitas because people know that you make premature conclusions. (Principal Scientist 2).

This need for diligence and rigour was attributed to the nature of scientific training, as the scientist went on to explain: 
What you absolutely do not do is write informal comments about what you think is going to happen on a forum and you're trained to not do that as a scientist and if you do start doing it you're going to start finding that your managers start reining you back in as well, because your managers are going to want to sign off reports before they're shared. They don't want you to start putting thoughts on a forum ... it would be inappropriate from a scientific point of view to put preliminary findings on a forum before you've rigorously done the science. (Principal Scientist 2)

The foregoing also demonstrated a different form of peer pressure from the one described by the KMT who believed that scientists who did not participate would realize they were losing out on vital knowledge, and would therefore succumb to peer pressure to participate. Rather than put pressure on individuals to share, some scientists would put pressure on members of a community not to share unsubstantiated claims.

What invariably happens is that someone that likes to be processorientated and likes to be quality driven, starts to implement some rigour to these forums to stop people putting ad-hoc comments that can be misleading ...people are discouraged from putting comments up that are unsubstantiated and not verifiable by scientific rigour, which then kills the whole forum and it stagnates. (Principal Scientist 2)

According to this scientist, maintaining the ethos of sharing and collaboration paradoxically means accepting the very tenets they had been trained to eschew.

The forums need to be essentially unmanaged, barely moderated at all and people need to accept there'll be comments on there that are people's thoughts on where they think the science is going to go that hasn't been validated ... But because we always strive to do things correctly, we strive for quality, we strive for perfection, we strive to do things professionally all of those things discourage people to put their immediate beliefs and their immediate scientific thoughts and their feelings out. (Principal Scientist 2)

These contradictions reveal the fractured nature of the collaborative process, and demonstrate how the R\&D staff themselves struggled to reconcile the realities of social networking with the rigour of scientific norms in sharing knowledge. Similarly, they require management to understand that not only is knowledge situated in a complex web of practices and professional norms, but also that a culture of 'facilitation' which is essentially top-down is inherently problematic to the extent that it fails to engage with the scientists' everyday experience of knowledge-creation and sharing (see also Gherardi \& Nicolini, 2002). Concerns about intellectual property (IP) infringement found common ground between managers and scientists. 
The only time [access] is restricted is if there is IP involved, it is probably not shared as widely until the product is properly developed. (Process Systems Manager)

Sometimes there are maybe patent issues, things that maybe will restrict those sorts of discussions. But on the whole and certainly in the project teams that I've worked in, I've found people to be quite open. (Principal Scientist 1)

Sometimes when you're working on things that are that new it's a good idea not to have everyone aware of what you're doing because it then ceases to be confidential when it starts to creep into the public domain. But normally if you feel that a skill set is missing, then it's important to share....you normally seek out who might be an expert and invite them to join you rather than display it to everybody in the company saying 'does anyone have any ideas on this? ... you need to lock down the intellectual property. (Polymer Chemist)

This scientist cited an additional concern about inadvertent knowledge leakage when individuals interacted with outsiders.

Information escaping from your organization is your main fear. The trouble is we have a lot of people who go and meet suppliers or talk to other people. So if we know that a group of people are working on this... even if it's just in conversation, sometimes it can be enough to just say 'oh Confect are doing that' ... but the trouble is you can't control where some of that information goes. (Polymer Chemist)

The above perspective is particularly important as it demonstrated that the scientists were protective of the knowledge and the portal within which it was created. They were prepared to police Confect-Portal to ensure the integrity of the system, both for the sake of the organization and also for their own job security and professional reputation. They had effectively tied their professional identity and destiny to the commercial success of the organization. Symbolic violence was thus assured and realized. We develop this analysis in more detail below.

\section{Symbolic violence in a context of knowledge appropriation}

The KM team use the symbolic power available to them to characterize Confect-Portal as a 'space of possibles' which functions 'as a system of common reference' (Bourdieu, 1993, p. 176), for sharing knowledge and defining how R\&D scientists behave. They ensured that the real purposes of appropriating knowledge and re-affirming the extant structure of power relations are misrecognized for what they really are. Furthermore, we suggest that these initiatives recursively define what constitutes capital, thus ensuring that managerial efforts to capture and absorb knowledge within Confect-Portal are at once mis-recognized and legitimized (Bourdieu, 1998). 
We observed above how collaborative efforts worked through socialization into a 'caring culture' as recognized both by management and the $R \& D$ staff. We examine this phenomenon with respect to the three elements of symbolic violence identified previously: pedagogy, misrecognition and the cultural arbitrary.

\section{The power of pedagogy}

Pedagogy is about learning, which is important for our purposes because it deals with the importance of sharing knowledge and networking. The portal brought with it a new form of language: terms like facilitation, networking, interaction, research community, enhanced trust, knowledge capture, project team and even the name Confect-Portal itself came to symbolize the reality the KMT was keen to create. This lingua franca inculcated the virtues of knowledgesharing and helped the scientists to forge their identity as knowledge-workers whether they engaged in Confect-Portal or not. By learning and accepting the language, they rendered the virtual knowledge-sharing space legitimate.

The complicity of organizational members thus elevated the rhetoric of facilitation and knowledge-sharing as part of the everyday reality of organizational functioning which started with the community of scientists, and was beginning to be acknowledged by other groups/divisions, in particular Human Resources, as reported by the KMT. Pedagogy works through a new form of language that is difficult to resist or reject because it appears 'neutral and normal' (Oakes et al., 1998, p. 272). The KMT sought to 'change what is at stake' by signalling that Confect was not just about generating new products; it was about how the firm constituted itself as a knowledge-sharing community. This was evident in the extensive media coverage, the public talks the GTD gave, the way the whole facilitation narrative was promulgated across the entire organization, as well as assessing managers on the extent to which they facilitated knowledge-sharing. When the learning fails to achieve the desired objectives, control can always be reinforced: when facilitation dries up, 'you [...] need continuity through management initiative' (GTD).

The ultimate purpose of pedagogy as a mechanism for symbolic violence is to realize and legitimize control that works through complicity. This pursuit of legitimacy through the imposition of ideals built into a platform expected to play a unifying role and which is defined by misrecognition, renders Confect-Portal ideological (see also Beyer, 1981; Kamoche \& Pinnington, 2012). We have shown how pedagogy relies on the socialization inherent in normative control, and suggest further that as a subtle control mechanism, it draws on the 'unconscious strivings' of employees (Willmott, 1993, p. 523) who are inspired to internalize 
the culture because failure to do so would be tantamount to questioning their very identity as a community of scientists. Thus, accepting rather than rejecting the virtual space allowed them to affirm and sustain the definitive characteristics of their identity, and to secure legitimacy for their own creative output. We see parallels here with the blend of 'soft controls' and formal bureaucratic practices to avoid 'contestation' and thus seek legitimacy for managerial strategies (Courpasson, 2000). At Confect, management achieved an important goal of enabling the scientists to appropriate the 'managerial frame' rather than to resist it, which in turn meant alignment with organizational control (Chreim, 2006).

\section{The nature of misrecognition}

The elements of control and misrecognition, which we consider to be inter-related, are particularly pertinent to this case study. With regard to control, its effects are echoed in Barker's (1993, p. 435) description of concertive control which creates 'an iron cage whose bars are almost invisible to the workers it incarcerates.' However, power and domination do not exist 'only in terms of asymmetry of domination [...] Domination, therefore implies action rather than submission' (Courpasson, 2000, p. 144). Therefore, from a symbolic violence perspective, it could be argued that workers assume or are given license to reconfigure the bars as they deem fit: they participate on their own terms, rather than reject the 'iron cage' outright. This echoes prior findings on how professionals co-opt and adapt bureaucratic procedures (eg Doolin, 2000; Waring and Currie, 2009). The scientists at Confect in effect misrecognize the KMT's motive for creating the iron cage in the first place. An example of management concealing or downplaying the pursuit of power/control is in the GTD's exhortations to share knowledge 'without letting the employees feel that managers are applying too much control', which signals the intent to conceal or deny. Thus, symbolic violence manifested itself in its appeal for complicity via 'voluntary participation' while effectively mis-recognizing the inherent power relations that sustained and legitimized the knowledge-sharing and networking system. For Kerr and Robinson (2012), economic and symbolic violence were misrecognized as desirable capital for effective decision making.

Bourdieu and Boltanski (1975) apply the concept of reconnaissance sans connaissance (recognition without knowledge) to demonstrate how those who would have resisted the new order (in this case knowledge-sharing through Confect-Portal) instead lend their complicity and accept its legitimacy; they do not possess full knowledge of the dynamics underpinning their action (as the managerial control strategy has been concealed or denied), and have 
ultimately mis-interpreted i.e. misrecognized the managerial intent behind the KMT knowledge-sharing portal. The complicity of the scientists, which is a form of acquiescence, becomes, through the lens of symbolic violence, an example of meconnaisance (misrecognition). This constitutes a significant achievement for the KMT: as a 'dominant' group, they determine the appropriate cultural capital ('membership' of Confect-Portal), but without expressly requiring the $R \& D$ scientists to enlist, succeed in securing their willing participation, in the same way society comes to accept social stratification reproduced by an educational system which is essentially an extension of primary socialization (Bourdieu \& Passeron, 1977; DiMaggio, 1979). Equally significantly, the KMT anticipated that 'peer pressure' would ensure that the potential dissenters were in no position to reject it, even though the pressure ultimately manifested itself differently but achieved the desired result. The KMT expected that not only would the bars of the iron cage become truly invisible in Barker's (1993) terms, but that the 'inmates' would police the iron cage through 'peer pressure' to ensure the potential dissenters did not resist by failing to participate in the portal.

Misrecognition can manifest itself in more overt forms, e.g. through a culture of fear, public humiliations and hard-nosed management (Kerr \& Robinson, 2012), by invoking public sympathy and affective relations amongst loyal followers (Robinson \& Kerr, 2009), or by construing commercial pursuits as service to God (Kamoche \& Pinnington, 2012). At Confect, failure to collaborate successfully is perceived in a poor light because such individuals lose the respect of their peers, an indictment on their professionalism and identity. This serves as an effective form of control, and is consistent with Bourdieu's view of symbolic violence as 'the most economical mode of domination' (Bourdieu, 1977, p. 192). It is economical because it relies on little or no effort on the part of the dominant party, yet it is effective because the dominated internalize the desired behavioural change and act accordingly.

\section{The 'cultural arbitrary'}

Bourdieu (1977) and Bourdieu and Passeron (1977) use the notion of a 'cultural arbitrary' to explain how the French educational system realizes the interests of the dominant groups/classes, reproducing while masking its contribution to these interests. Misrecognition illustrates the effect of imposing a 'cultural arbitrary' to express the objective interests of the dominant groups/classes (the KMT), while concealing its role in securing control. At Confect, misrecognition took place to the extent that the cultural arbitrary concealed its role in securing control and knowledge appropriation, but, ironically, was assisted by the fact that the scientists 
protected their own interests as well. This represents an unanticipated aspect of symbolic violence, which we examine below with regard to resistance.

A cultural arbitrary also operates by denying yet rendering certain ideas as 'unthinkable'. According to Oakes et al. (1998) museums and cultural heritage sites portray themselves as a 'business', yet treat as 'unthinkable' ideas such as 'being business-like', 'efficiency', etc. They pursue yet conceal economic capital, thus demonstrating the notion of misrecognition. At Confect this ethos was captured in comments that downplayed the significance of tangible rewards, technology and even business results, thus rendering Confect-Portal the character of a Bourdieusian cultural arbitrary. This is exemplified in the Technologies and Engagement Manager's comments cited earlier. Furthermore, this manager was keen to emphasize the view that scientists were not driven by productivity and rewards:

'scientists did not just expect a raise, or something ... We are a fun company, we do make fun products. We want to make sure technology doesn't take over.'

Similarly a Knowledge Management Champion reported:

'When it comes to sharing knowledge, technology isn't relevant at all. It's not the main driver or inhibitor of knowledge-sharing. It's about the intimacy, and closeness of colleagues sharing personal experiences, not obsessed with business results and technology such that when technology fails no one can work. We want to create opportunities for social engagement, conversations, etc.'

Also, by insisting that performance evaluation mechanisms and rewards were not brought into the equation, management invoked the cultural arbitrary which concealed these ideas as 'unthinkable' and encouraged the belief that the purpose of Confect-Portal was simply to provide researchers the space to share knowledge. Yet, if the knowledge did not translate into marketable products, it is doubtful whether the organization would have continued to support it. Similarly, Kamoche and Pinnington (2012) argue that when proponents of organizational spirituality deny the centrality of profits and productivity, while claiming that the purpose of business is to serve God, they are invoking a 'cultural arbitrary' rooted in symbolic violence.

The scientists were also categorical: they were not motivated by personal financial gain or organizational performance, but instead saw their identity as scientists engaged in innovation through networking. This view also demonstrates that the control mechanism in place differs 
from concertive control which explicitly rewards specified forms of behaviour, thus demonstrating further the 'value-added' of our analysis. Without implying manipulation on the part of the KMT (which in any case, would be inconsistent with Bourdieu's conception of symbolic violence), we argue that the scientists are placed in a situation where the denial or rejection of Confect-Portal as the right way to order their working life through collaboration and networking is rendered 'unthinkable'.

\section{Compliance as discursive resistance}

Organizations do not merely rely on cultural conformity but other forms of control which, nevertheless inspire some form of dissent (Fleming, 2012). This section considers how resistance is construed as a response to symbolic violence. While research that treats resistance as efforts to limit the influence of managerial power (Ackroyd, 1996), is still valid, an emerging critique has challenged the unquestioning perspective of resistance as the rejection of practices, policies and new-fangled change initiatives by disgruntled workers (see Ezzamel, Willmott, \& Worthington, 2001; Symon, 2005; Thomas \& Davies, 2005). This suggests a shift from structuralist explanations to an engagement with subjectivity and discursive practices. Resistance may manifest itself through rhetorical devices (Symon, 2005), can be theorized at the level of meanings and subjectivities (Thomas \& Davies, 2005), and can occur to defend or express identity (Alvesson \& Willmott, 2002; Ezzamel et al., 2001), as at Confect, and where subjectivities are important, but not fixed constructs (Ball \& Wilson, 2000; Clegg, 1994).

The scope for resistance exists not because of some pre-existing structural asymmetry, but because the KMT lacked a complete picture of the scientists' reality of knowledge-sharing practices and ethos. The KMT believed there was too much information, and that ConfectPortal was a dynamic platform for networking; the scientists had alternative mechanisms for networking and sometimes saw the portal as a static archive/repository, 'not conversational', 'not interactive'. Furthermore, the initial response to the culture of top-down sharing, or in the words of the GTD, to 'push people into sharing' was resisted, and it only gained acceptance when it was left to their discretion; only then did compliance materialize, on their own terms.

We found that peer pressure worked in unexpected ways. Consistent with symbolic violence, peer pressure ultimately worked not merely by compelling scientists to participate in knowledge-sharing, but to participate in a conscientious manner whereby they protected themselves from deleterious politics, protected identity interests - reputation and 'gravitas', hence their own capital in a contested field (Bourdieu, 1993), while also realizing the interests 
of the dominant group, i.e. the organizational asset of intellectual property rights. We interpret the actions of the R\&D scientists as acceptance that participating in knowledge-sharing on Confect-Portal through collaboration and networking is consonant with their identity as creators of scientific knowledge. Their response to the virtual space was informed by their individual dispositions in terms of who they were as (highly skilled, mostly autonomous, reputation-conscious) scientists. Thus, the form of resistance to be inferred was not a rejection of managerial strategy to use and legitimize Confect-Portal, but a discursive compromise which echoed the adoption/adaptation of bureaucratic procedures, subsumed agency, and re-affirmed their identity. In Fleming's (2012) terms, resistance was not a cynical response to corporate culturalism, but was tied to something akin to 'life itself', and specifically, the scientists' identity. Thus, while compliance constituted a form of discursive resistance, ultimately it demonstrates the effectiveness of symbolic violence as a control mechanism for professionals.

\section{Conclusion}

The creation and appropriation of knowledge is defined by contests over meaning, identity and 'ownership', especially where 'property rights' are ill-defined and ambiguous (Bowman \& Swart, 2007; Grant, 1996). Yet, the role of managerial control in these processes has not always been understood as researchers have tended to assume that professionals can be managed through socialization, rewards and 'congruent' values and norms. In an attempt to go beyond extant forms of control we drew from Bourdieu's social theory to examine how knowledgesharing exhortations might be interpreted as an appeal for complicity which worked because the scientists tied their involvement in the portal to the way they defined themselves, a process which allowed them to protect their capital in Bourdieusian terms. We examined how an organization sought to strengthen the way it appropriates knowledge from its R\&D scientists not by requiring them to participate in its new-fangled virtual space, nor by proffering (financial) incentives as in prior conceptions of normative/concertive control, but by seeking to facilitate a subtle blend of 'voluntary participation' and presumed 'peer pressure'. This approach, which we interpret as 'symbolic violence', appeared to rely implicitly on the idea of seeking voluntary compliance by motivating individuals to collaborate and re-affirm their sense of identity within the virtual space (cf Dyer and Nobeoka, 2000). The knowledge management team not only sought acceptance for a virtual knowledge-sharing space, but also, in the process, realized the legitimacy of their efforts to appropriate knowledge. The creation of Confect-Portal must therefore be interpreted not merely as a virtual space to create and share knowledge but 
an arena within which the managerial prerogative in knowledge appropriation comes to be reaffirmed through symbolic violence.

The scientists came to accept the legitimacy of the portal as part of their everyday work, and it became, for them, the right way to think and behave, even though their motives for doing so were somewhat at odds with those advanced by management. Following Bourdieu and Passeron (1977, p. 206) we contend that accepting the rationale for sharing and networking justifies the existence of Confect-Portal while misrecognizing the ultimate purpose which is to create and appropriate codifiable knowledge, rather than merely to share it. By appealing to the scientists' sense of identity and by counting on their inherent tendency to police themselves as professionals, the risk of overt resistance is effectively neutralized. The scientists not only take pride in their ability to collaborate and derive satisfaction from the subsequent product outcomes; they also disregard the opportunity to make self-interested appropriative claims on their knowledge beyond deriving intrinsic satisfaction and symbolic rewards. This scenario reveals an ideological ethos in the way both management and the scientists subscribe to the 'shared' interest of networking and knowledge-sharing while ignoring the fact that efforts to appropriate knowledge constitute a reconfiguration of material interests (Beyer, 1981). Hence, the potential incongruity of the scientists' and Confect's interests is swept under the ideological carpet by the broom of 'facilitation' which acts as a surrogate for control.

In terms of limitations and further research, we acknowledge that the relatively small number of scientists we were allowed to speak to is not necessarily representative of the entire population of the community in question. We hope, however, that this paper has furthered our understanding of organizational control, knowledge sharing, and Bourdieusian social theory in a field that has tended to assume 'value consensus' in sharing knowledge. Further research could examine how the insights generated here might be tied to the theory of knowledge as situated practices in order to further interrogate the context of the knowledge-creators (e.g. Gherardi \& Nicolini, 2002). Such an enterprise would be fruitful to the extent that 'the human agent's understanding resides, first and foremost, in the practices in which he participates' (Tsoukas, 1996, p. 16). However, following Ringberg and Reihlen (2008) we acknowledge the role of cognitive processes in making sense of knowledge embedded in practices, and propose that further research might consider how cognitive processes might be incorporated into a conception of knowledge-users' predispositions, hence Bourdieusian habitus.

We hope to engender further research into the problematic nature of exhortations to share knowledge in different organizational contexts, especially where such sharing is instigated centrally and fails to take adequate account of the everyday practices, sense-making abilities, 
as well as interests of those being asked to share knowledge. Research in this genre will enhance our understanding of the realities of knowledge-appropriation as knowledge comes to be understood more and more not merely as a source of competitive advantage but also as a contested asset. We have focused on managerial control strategies as constituting symbolic violence. Yet, relations of domination can be construed in a variety of ways, involving a reversal of roles, rather than 'top-down control, bottom-up resistance'. Thus, in addition to scenarios in which professionals re-enact bureaucratic procedures or are perceived as more powerful than managers, further research might consider power relations amongst professionals who are engaged in developing their own knowledge-sharing portal, how symbolic violence manifests itself amongst seemingly homogenous communities where power asymmetries exist along disciplinary boundaries and reflect different levels of expertise, and how groups use symbolic violence towards management or other groups.

We see Bourdieu's work providing significant opportunities to interpret organizational action or re-interpret prior studies on power and control. For example, Waring and Currie (2009, p. 774) state that as professionals internalize management techniques, 'it negates the need for top-down management controls over professionals as it fosters conformity from within professional work' - we see this as the essence of symbolic violence. However, we are aware that some scholars consider Bourdieu's work obscure, methodologically imprecise, and even incoherent (e.g. Alexander, 1995; DiMaggio, 1979; Fowler, 2000; Thompson, 1984). Calhoun (1995) argues that symbolic violence implies determinism, yet as Oakes et al. (1998) point out, for Bourdieu, strategizing to obtain important positions does not imply rational calculative decision-making. This claimed indeterminacy suggests the need for caution in interpreting the behaviour of the Confect scientists and the need for further research into agents' behaviour where symbolic violence does not, as DiMaggio (1979) argues, provide for social change. Drawing from Bourdieu's work does not mean an acritical acceptance of his thesis. Thus, contrary to Bourdieu's position, the Confect case demonstrates that symbolic violence does not necessarily imply undermining the capital of the 'dominated'. In fact, our reflexive approach demonstrates how the 'dominated' ultimately acquire the capacity to strengthen their capital by defining the nature and scope of their engagement with the portal.

Further research might also consider how scientists' habitus, in particular their dispositions from past socialization, determines their decision to share or not to share knowledge, and how managers can begin to comprehend the specific nature of 'discursive practices' (Tsoukas, 1996) of sharing knowledge that come to be accepted by scientists through their application in the everyday discourse of creating new products, yet remain largely alien to managers. A related 
issue is the important practical implication of involving end-users in the creation of knowledge management systems, which did not happen at Confect. In closing we note that our analysis has relevance not merely for the individual orientations to sharing knowledge and networking, but also for other organizational communities/professionals where groups are pitted against each other and where relations are defined by contests over capital. Further research might examine how other categories of both 'dominants' and 'dominated' negotiate their relationship at work vis-à-vis the reality of the contested terrain of facilitation and similar tools of control, thus leading to a more discursive approach to knowledge appropriation and power relations.

\section{References}

Ackroyd, S. (1996). Organization contra organizations: professions and organizational change in the United Kingdom. Organization Studies, 17, 599-621.

Alexander, J. C. (1995). Fin de siècle social theory: relativism, reduction, and the problem of reason. London: Verso

Alvesson, M. (2001). Knowledge work: ambiguity image and identity. Human Relations, 54, 863-886.

Alvesson, M. (1993). Organization as rhetoric: knowledge-intensive companies and the struggle with ambiguity. Journal of Management Studies, 30, 997-1015.

Alvesson, M. \& Willmott, H. (2002). Identity regulation as organizational control: producing the appropriate individual. Journal of Management Studies, 39, 619-644.

Ambrosini, V. \& Bowman, C. (2001). Tacit knowledge: some suggestions for operationalization. Journal of Management Studies, 38, 811-829.

Ball, K. \& Wilson, D. C. (2000). Power, control and computer-based performance monitoring: repertoires, resistance and subjectivities. Organization Studies, 21, 539-565.

Barker, J. R. (1993). Tightening the iron cage: concertive control in self-managing teams. Administrative Science Quarterly, 38, 408-437.

Bartunek, J. M. (2002). The proper place of organizational scholarship: a comment on Hinings and Greenwood. Administrative Science Quarterly, 47, 422-427.

Bell, D. (1973). The coming of the post-industrial society: a venture in social forecasting. New York, NY: Basic Books.

Beyer, J. M. (1981). Ideologies, values, and decision making in organisations. In P. C. Nystrom \& W. H. Starbuck (Eds.) Handbook of organisational design, (pp. 166-202). New York, NY: Oxford University Press. 
Boltanski, L. (1984). How a social group objectified itself: "cadres" in France, 1936-45. Social Science Information, 23, 469-492.

Bourdieu, P. (1998). Practical reason. Cambridge: Polity Press.

Bourdieu, P. (1993). The field of cultural production. New York, NY: Columbia University Press.

Bourdieu, P. (1991). Language and symbolic power. Cambridge: Polity Press.

Bourdieu, P. (1977). Outline of a theory of practice. Cambridge: Cambridge University Press.

Bourdieu, P. \& Boltanski, L. (1975). Le fetichisme de la langue. Actes, 4, 2-32.

Bourdieu, P. \& Boltanski, L. (1984). Le fetichisme de la langue. Actes, 1975, 4, 2-33. Cited in Thompson, J. B. Studies in the theory of ideology. Cambridge: Polity Press.

Bourdieu, P. \& Passeron, J.-C. (1977). Education, society and culture. London: Sage.

Bowman, C. \& Swart, J. (2007). Whose human capital? The challenge of value capture when capital is embedded. Journal of Management Studies, 44, 488-505.

Brivot, M. (2011). Controls of knowledge production, sharing and use in bureaucratized professional service firms. Organization Studies, 32, 489-508.

Brown, A. \&. M.A. Lewis (2011) Identities, discipline and routines. Organization Studies, 32: 871-895.

Calhoun, C. (1995). Critical social theory: culture, history, and the challenge of difference. Cambridge, MA: Blackwell.

Chreim, S. (2006). Managerial frames and institutional discourses of change: employee appropriation and resistance. Organization Studies, 27, 1261-1287.

Clegg, S. R. (2002). Lives in the balance: a comment on Hinnings and Greenwood's "Disconnects and consequences in organization theory?" Administrative Science Quarterly, $47,428-441$.

Clegg, S. R. (1994). Power relations and the constitution of the resistant subject. In J. Jermier, D. Knights, \& W. Nord (Eds.) Resistance and power in organizations, (pp. 48-60). London: Routledge.

Collins, C. J. \& Smith, K. G. (2006). Knowledge exchange and combination: the role of human resource practices in the performance of high-technology firms. Academy of Management Journal, 49, 544-560.

Collinson, D. (1994). Strategies of resistance: power, knowledge and subjectivity in the workplace. In J. Jermier, D. Knights, \& W. Nord (Eds.) Resistance and power in organizations, (pp. 25-68). London: Routledge. 
Cooper, M. (2008). The inequality of security: winners and losers in the risk economy. Human Relations, 61, 1229-1258.

Courpasson, D. (2000). Managerial strategies of domination: power in soft bureaucracies. Organization Studies, 21, 141-161.

Currie, G. \& Kerrin, M. (2003). Human resource management and knowledge management: enhancing knowledge sharing in a pharmaceutical company. International Journal of Human Resource Management, 14, 1027-1045.

Delbridge, R. \& Ezzamel, M. (2005). The strength of difference: contemporary conceptions of control. Organization, 12, 603-618.

DiMaggio, P. (1979). On Pierre Bourdieu. American Journal of Sociology, 84, 1460-1474.

Doolin, B. (2002) Enterprise discourse, professional identity and the organizational control of hospital clinicians. Organization Studies, 23: 369-390.

Drazin, R. (1990). Professionals and innovation: structural-functional versus radicalstructural perspectives. Journal of Management Studies, 27, 245-263.

Drucker, P. (1993) Post-capitalist society. Oxford: Butterworth-Heinemann.

Dyer, J. H. \& Nobeoka, K. (2000). Creating and managing a high performance knowledgesharing network: the Toyota case. Strategic Management Journal, 21, 345-367.

Dyer, W. G., Jr. \& Wilkins, A.L. (1991). Better stories, not better constructs, to generate better theory: a rejoinder to Eisenhardt. Academy of Management Review, 16, 613-19.

Easterby-Smith, M., Thorpe, R. \& Lowe, A. (1991). Management research: an introduction. London: Sage.

Easterby-Smith, M. (1994). Evaluating management development, training and education, Aldershot, Hampshire: Gower.

Eisenhardt, K. M. (1989). Building theories from case study research. Academy of Management Review, 14, 532-50.

Emirbayer, M. \& Johnson, V. (2008). Bourdieu and organizational analysis. Theory and Society, 37, 1-44.

Etzioni, A. (1964). Modern organizations. Englewood-Cliffs, NJ: Prentice-Hall.

Ezzamel, M., Willmott, H., \& Worthington, F. (2001). Power, control and resistance in 'the factory that time forgot'. Journal of Management Studies, 38, 1053-1079.

Fleming, P. (2012) 'Down with Big Brother!' The end of 'Corporate Culturalism'? Journal of Management Studies, 50: 474-495. 
Fleming, P. \& Sturdy, A. (2011). Being yourself in the electronic sweatshop: new forms of normative control. Human Relations, 64, 177-200.

Foucault, M (1977). Discipline and punish: the birth of the prison. London: Allen Lane.

Foss, J. N., Husted, K., \& Michailova, S. (2010). Governing knowledge sharing in organizations: levels of analysis, governance mechanisms, and research directions. Journal of Management Studies, 47, 455-482.

Fowler, B. (Ed.) (2000) Reading Bourdieu on society and culture. Oxford, UK: Blackwell.

Gabriel, Y. (2000). Storytelling in organizations: facts, fictions and fantasies. Oxford, UK: Oxford University Press.

Galbraith, J. (1967). The new industrial state. Boston, MA: Houghton Mifflin.

Gherardi, S. \& Nicolini, D. (2002). Learning the trade: a culture of safety in practice. Organization, 9, 191-223.

Grant, R. M. (1996). Toward a knowledge-based theory of the firm. Strategic Management Journal, 17, 109-122.

Grey, C. \& Garsten, C. (2001). Trust, control and post-bureaucracy. Organization Studies, 2, 229-250.

Hansen, M. T. (2002). Knowledge networks: explaining effective knowledge sharing in multiunit companies. Organization Science, 13, 232.

Hinings, C.R. \& Greenwood, R. (2002) Disconnects and consequences in organization theory? Administrative Science Quarterly, 47, 411-421.

Inkpen, A. C. \& Tsang, E. W. K. (2005). Social capital, networking, and knowledge transfer. Academy of Management Review, 30, 146-165.

Jermier, J., Knights, D., \& Nord, W. (Eds.) (1994) Resistance and power in organizations. London: Routledge.

Kamoche, K. \& Pinnington, A. (2012). Managing people 'spiritually': a Bourdieusian critique. Work, Employment and Society, 26, 497-513.

Kamoche, K. \& Maguire, K. (2011). Pit sense: appropriation of practice-based knowledge in a UK coalmine. Human Relations, 64, 725-744

Kerr, R. \& Robinson, S.K. (2012). From symbolic violence to economic violence: the globalizing of the Scottish banking elite. Organization Studies, 33,247-266.

Kerr, R. \& Robinson, S.K. (2009). The hysteresis effect as creative adaptation of the habitus: Dissent and transition to the 'corporate' in post-Soviet Ukraine, Organization, 16, 829-853. 
Konstantinou, E. \& Fincham, R. (2010). Not sharing but trading: Applying a Maussian exchange framework to knowledge management. Human Relations, 64: 823-842.

Kunda, G. (1992). Engineering culture: control and commitment in a high-tech corporation. Philadelphia, PA: Temple University Press.

Lampel, J. \& Meyer, A. D. (2008). Field-configuring events as structuring mechanisms: how conferences, ceremonies, and trade shows constitute new technologies, industries, and market. Journal of Management Studies, 45, 1025-1035.

McLeod, C., O'Donohue, S., \& Townley, B. (2009). The elephant in the room? Class and creative careers in British advertising agencies. Human Relations, 62, 1011-1039.

McLoughlin, I. P., Badham, R. J., \& Palmer, G. (2005). Cultures of ambiguity: design, emergence and ambivalence in the introduction of normative control. Work, Employment and Society, 19, 67-89.

Moore, R. (2004). Cultural capital: objective probability and the cultural arbitrary. British Journal of Sociology of Education, 25, 445-456.

Morean, B. (2009). The organization of creativity in Japanese advertising production. Human Relations, 62, 963-985.

Mutch, A. (2003). Communities of practice and habitus. Organisation Studies, 24, 383-303.

Nonaka I. \& Takeuchi, H. (1995). The knowledge creating company. Oxford: Oxford University Press.

O'Mahoney, J. (2007). Constructing habitus: the negotiation of moral encounters at Telekom. Work, Employment and Society, 21, 479-496.

Oakes, L. S., Townley, B., \& Cooper, D. J. (1998). Business planning as pedagogy: language and control in a changing institutional field. Administrative Science Quarterly, 43, 257-292.

Ouchi, W. G. (1980). Markets, bureaucracies, and clans. Administrative Science Quarterly, $25,129-141$.

Ouchi, W. G. (1979). A conceptual framework for the design of organizational control mechanisms. Management Science, 25, 833-848.

Pinnington, A. H., Kamoche, K., \& Suseno, Y. (2009). Property in knowledge work: an appropriation-learning perspective. Employee Relations, 31, 57-80.

Raelin, J. A. (2011). The end of managerial control? Group \& Organization Management, $36,135-160$.

Ragin, C. C. (1994). Constructing social research. London: Pine Forge Press.

Reed, M. I. (1996). Expert power and control in late modernity: an empirical review and theoretical synthesis. Organization Studies, 17, 573-597. 
Ringsberg, T. \& Reihlen, M. (2008). Towards a socio-cognitive approach to knowledge transfer. Journal of Management Studies, 45, 912-935.

Robertson, M. \& Swan, J. (2003). Control - what control? Culture and ambiguity within a knowledge-intensive firm. Journal of Management Studies, 40, 831-858.

Robinson, S. K. \& Kerr, R. (2009). The symbolic violence of leadership: a critical hermeneutic study of leadership and succession in a British organization in the post-Soviet context. Human Relations, 62, 875-903.

Schultze, U., \& Stabell, C. (2004). 'Knowing What You Don't Know? Discourses and Contradictions in Knowledge Management Research.' Journal of Management Studies, 41: 549-573.

Sewell, G. (1988). The discipline of teams: the control of team-based industrial work through electronic and peer surveillance. Administrative Science Quarterly, 43, 397-428.

Shamir, B. (1991). Meaning, self and motivation in organizations. Organization Studies, 12, 405-424.

Swan, J., Scarbrough, H., \& Robertson, M. (2002). The construction of "communities of practice" in the management of innovation. Management Learning, 33, 477-496.

Symon, G. (2005). Exploring resistance from a rhetorical perspective. Organization Studies, 26, 1641-1663.

Tallman, S. \& Phene, A. (2007). Leveraging knowledge across geographic boundaries. Organization Science, 18, 252-260.

Thomas, R. \& Davies, A. (2005). Theorizing the micro-politics of resistance: new public management and managerial identities in the UK public services. Organization Studies, 26, 683-706.

Thompson, J. B. (1984). Studies in the theory of ideology. Cambridge: Polity Press.

Townley, B., Beech, N. \& McKinlay, A. (2009). Managing in the creative industries: managing the motley crew. Human Relations, 62, 939-962.

Tsoukas, H. (1996). The firm as a distributed knowledge system: a constructionist approach. Strategic Management Journal, 17, 11-25.

Turner, K. L. \& Makhija, M. V. (2006). The role of organizational controls in managing knowledge. Academy of Management Review, 31, 197-217.

Wacquant, L. (2002). De l'ideologie a la violence symbolique: Culture, class et conscience chez Marx et Bourdieu. In J. Lojkine (Ed.) Les sociologies critiques du capitalisms (pp. 2540). Paris: Presses Universitaires de France. Cited in Robinson, S. K. \& Kerr, R. (2009). The symbolic violence of leadership: a critical hermeneutic study of leadership and succession in a British organization in the post-Soviet context. Human Relations, 62, 875-903. 
Waring, J. \& Currie, G. (2009). Managing expert knowledge: organizational challenges and managerial futures for the UK medical profession. Organization Studies, 30, 755-778.

Wiener, Y. (1982). Commitment in organizations: a normative view. Academy of Management Review, 7, 418-428.

Willmott, H. (1993). Strength is ignorance; slavery is freedom: managing culture in modern organizations. Journal of Management Studies, 30, 515-552.

Yin, R. K. (1994). Case study research: design and methods. Thousand Oaks, CA: Sage. 